\title{
STRATEgic Nonlinear InCOME TAX COMPETITION WITH PeRfeCt LABOR MOBILITY
}

\author{
by
}

Craig Brett and John A. Weymark

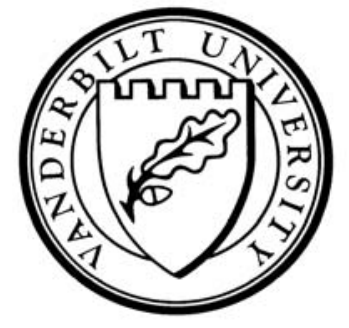

Working Paper No. 08-W12

August 2008

\section{DEPARTMENT OF ECONOMICS \\ VANDERBILT UNIVERSITY \\ NASHVILLE, TN 37235}

www.vanderbilt.edu/econ 


\title{
Strategic Nonlinear Income Tax Competition with Perfect Labor Mobility*
}

\author{
by \\ Craig Brett \\ Department of Economics, \\ Mount Allison University, \\ 144 Main Street, Sackville NB, E4L 1A\%, Canada \\ (e-mail: cbrett@mta.ca) \\ and \\ John A. Weymark \\ Department of Economics, Vanderbilt University, \\ VU Station B \#35189, 2301 Vanderbilt Place, \\ Nashville, TN 37235-1819, U.S.A. \\ (e-mail: john.weymark@vanderbilt.edu)
}

August 2008

*We are grateful to the Canada Research Chairs Programme and the Social Sciences and Humanities Research Council of Canada for their generous financial support. We have benefited from the comments of Felix Bierbrauer and Mike Hoy, as well as from those individuals in attendence when this research was presented at the University of the Basque Country, the University of Vigo, the Canadian Public Economics Group conference at Simon Fraser University, and the World Congress of the Game Theory Society at Northwestern University. 


\begin{abstract}
"Strategic Nonlinear Income Tax Competition with Perfect Labor Mobility"

by

Craig Brett and John A. Weymark
\end{abstract}

The Nash equilibria of a tax-setting game between two governments who can set nonlinear income tax schedules for a perfectly mobile workforce whose members differ in unobserved skill levels are examined. Each government maximizes the average utility of its residents. It is shown that while equilibria exist, there do not exist equilibria in which either the most highly skilled pay positive taxes or the lowest skilled receive transfers. It is also shown that it is possible for the most highly skilled to receive a net transfer funded by taxes on lower skilled individuals in equilibrium.

Journal of Economic Literature classification: D82, H21, H87

Keywords and phrases: income tax competition, labor mobility, optimal income taxation, race to the bottom. 


\section{Introduction}

There is widespread concern that tax competition among jurisdictions for mobile capital and labor places severe constraints on the ability of these jurisdictions to engage in substantial redistributive taxation, to provide welfare programs for the needy, to maintain high safety and environmental standards, and to regulate labor practices, among other desiriable social objectives. In other words, tax competition results in a "race to the bottom." The importance of this phenomenon in the context of interjurisdictional competition among communities in the same country was recognized by Stigler (1957), but it is also a familiar feature of competition between national governments. With an ever expanding European Union, barriers to mobility across national boundaries within Europe are eroding. ${ }^{1}$ Similarly, restrictions on the free flow of capital around the world are diminishing. These developments have been accompanied by increased worries that the welfare state will wither and die due to the inability of national governments to maintain their social policies as the impediments to capital and labor mobility are relaxed. It is therefore important to determine the extent to which these concerns are justified.

There is a substantial literature that investigates the constraints that the competition between governments for mobile capital and labor places on the ability of governments to raise tax revenue and redistribute income. For the most part, this body of research assumes that there is full information about the relevant characteristics of the agents in the economy. For an overview of the main issues considered and a review of what has been learned in this literature, see Cremer and Pestieau (2004) and Wildasin (2006a). However, in the context of redistributive income taxation, it is not only the tax policies of foreign governments that constrain the design of a country's income tax schedule by creating incentives for the wealthy to emigrate or the foreign poor to immigrate. As emphasized by Mirrlees (1971), the inability of a government to distinguish workers with different skills also limits the amount of redistribution that is possible. Surprisingly, very little attention has been directed to investigating the validity of the race-to-the-bottom thesis in the presence of such information asymmetries when labor is internationally mobile.

In this article, we investigate tax competition between two national governments who set nonlinear income tax schedules when individuals of all skills are perfectly mobile between the two countries. In this context, the race-to-the-bottom thesis says that the ability of the national governments to engage in substantial redistribution will be severely constained by the competition between them.

Our model is designed to highlight the forces of competition between two countries in a world in which, without competition, taxation would be redistributive in the sense that individuals with the highest level of innate ability would pay more taxes than less skilled individuals and individuals with the lowest level of innate ability would receive

\footnotetext{
${ }^{1}$ The importance of international migration for OECD countries is apparent from the data presented in Wildasin (2006b). For example, he documents that gross migration flows for most European Union countries exceeded 0.5 percent of total population in 2000, and in some cases exceeded 1 percent.
} 
transfers. We consider a discrete type version of the model used in the seminal paper of Mirrlees (1971) to analyze optimal nonlinear income taxation for a closed economy. However, there are now two tax-setting governments instead of one and individuals may freely choose their countries of residence. There is perfect labor mobility in two senses: (1) no resources need to be expended in order to move and (2) there are no frictions to mobility based on residential attachments. We assume that it is only possible for a government to tax the income at source of its residents. It is not possible to tax the earnings of citizens who reside in the other country, nor do such individuals make remittances to their relatives in the country of origin. We further assume that the labor productivity of an individual does not depend on the country of residence. When combined with our assumption that labor is perfectly mobile, this assumption implies that locational decisions only depend on the tax schedules offered by the two countries, thereby allowing us to isolate the impact of adding interjurisdictional tax competition to the Mirrlees model without at the same time introducing other factors that might affect an individual's choice of country of residence.

Each government designs a tax schedule to maximize an average utilitarian social welfare function defined over the utilities of its residents, given the tax schedule in the other country, but taking full account of any mobility that might result from its choice. With fixed, immobile populations, this welfare criterion provides a motivation for transfering income from higher to lower skilled individuals. Free labor mobility leads to aggressive competition among the two countries. We show that this competition is sufficiently strong that in any Nash equilibrium of the tax competition game, it is impossible to extract positive tax payments from the highest skilled individuals or to provide transfers for the lowest skilled. An example of such an equilibrium is provided by the laissez-faire solution in which neither government taxes or subsidizes any individual. Competition for the most highly skilled is so intense that it is possible for the most highly skilled to receive a net transfer funded by taxes on lower skilled individuals in equilibrium.

Individuals make choices on two margins. The labor-leisure decision operates on the intensive margin, whereas the locational decision operates at the extensive margin. The labor-leisure decision is largely driven by marginal tax rates, whereas the locational decision is more sensitive to average rates of taxation. Because the adjustments at the extensive margin, not the adjustments at the intensive margin, are the driving force behind our results, we are confined to making statements about total tax liabilities.

Our results stand in sharp constrast to the findings of Hamilton, Lozachmeur, and Pestieau (2002). They show that there is no race to the bottom when the two countries choose linear income tax schedules to maximize a Rawlsian objective function when only the low skilled are mobile and these individuals do not work. However, the Rawlsian objective adopted is nonstandard. Governments are assumed to maximize the poll subsidy available to the low skilled, not to maximize the utility of the worst off residents. With the latter objective, no equilibrium with a positive poll subsidy exists because either government would want to lower its poll subsidy in order to induce the low skilled to move. 
To the best of our knowledge, there are only three other articles that consider strategic interaction among governments who can employ fully nonlinear income taxes when some individuals are free to choose both their country of residence and how much to work. ${ }^{2}$

Hamilton and Pestieau (2005) consider a political economy model of competition between a large number of small countries when there are two skill types and only one of them is mobile. The objective function of a government is determined by majority rule, with the consequence that it wants to maximize the utility of the type of individual who is in the majority. Hamilton and Pestieau focus on identifying what distributions of skill types communities can achieve in equilibrium.

Like us, Piaser (2007) studies nonlinear income tax competition by benevolent governments in the presence of labor mobility, but in a model with only two skills. However, there are important differences between our work and his that lead to more intense competition for the highly skilled in the problem that we consider. Piaser assumes that both countries are identical, both in the objective that they purse and in their initial skill distribution. He restricts attention to symmetric equilibria and, hence, while the potential for free movement of labor constrains what tax schedules are sustainable, nobody actually moves. In contrast to our assumption that labor is perfectly mobile, Piaser assumes that only one type of individual is mobile, but even for the mobile type, it is costly to move. Naturally, the introduction of moving costs softens tax competition, but it also provides a greater role for adjustments at the intensive margin to shape tax policy, which permits Piaser to make statements about equilibrium marginal tax rates, which we do not. Piaser considers two kinds of social welfare functions, one Rawlsian and one that evaluates outcomes by taking a weighted sum of the utilities of representatives of each type of individual, with the relative weight chosen so as to favor redistribution towards the low skilled. Both objectives have the feature that they are entirely indifferent to the number of individuals of a given type who reside in a country; all that matters is the utility achieved by each type. In constrast, with the average utilitarian criterion employed here, every resident counts positively. As a consequence, there is an incentive to compete for skilled individuals because, due to the incentive constraints that operate within a country, they have the highest utilities, and this would be the case even when increasing the number of skilled individuals residing in a country does not increase that country's tax revenue.

The only other article that considers nonlinear income tax competition with mobility of all skill types is Morelli, Yang, and Ye (2008). ${ }^{3}$ They suppose that individuals are uniformly distributed on a circle with two states located at extreme points of a diagonal of this circle. Individuals differ not only in their skills, but also in their attachments to their home country (which serves as a mobility cost), as measured by the distance to the nearest state. Morelli, Yang, and Ye are primarily interested in whether having unified taxation for both states or having tax competition between them would be chosen by majority

\footnotetext{
${ }^{2}$ Huber (1999) considers how competition for mobile capital affects the choice of an optimal nonlinear income tax schedule when labor is immobile.

${ }^{3}$ Our work and theirs was done independently.
} 
rule in a constitutional stage that determines this institutional design question. They assume that each government wants to maximize the total utility of those individuals that fall within its tax jurisdiction. Analytical results are obtained when there are three skill levels. In this case, the lowest skilled prefer the unitary government so as to receive a higher subsidy, whereas the highest skilled prefer tax competition so as to lower their tax payments. The middle class faces countervailing incentives. They want to receive transfers from the highest skilled, but do not want to subsidize the lowest skilled. As a consequence, which regime is chosen depends on the preferences of the middle class.

Considerably more attention has been devoted to the analysis of optimal income taxation with mobile labor in the absence of strategic competition between govenments. Early contributions to this literature include Bhagwati and Hamada (1982) and Wilson (1980) for the case of linear taxation and Mirrlees (1982) for the case of nonlinear taxation. Wilson (2006) provides an insightful interpretive survey of this literature. In much of this literature, potential emigrants choose between the best labour-consumption bundle available at home and some predetermined bundle or utility abroad. There is a potential conflict between a government's desire to tax on the basis of ability to pay and the possibility that more able individuals might emigrate to avoid high tax burdens. As shown by Wilson (1980) for linear taxation and by Wilson (1992) for nonlinear taxation, individual decisions made at the intensive and extensive margins can interact in complex ways, with the possiblity of migration by skilled individuals lowering their average taxes while at the same time raising their marginal tax rates compared to what would be the case in a closed economy. ${ }^{4}$ With strategic interaction, as in our model, decisions made at the extensive margin play an even more central role, further constraining the amount of redistribution that is possible compared to what would be the case when other jurisdictions act passively.

We present our model in Section 2. In Section 3, we demonstrate that there are no Nash equilibria in our tax-setting game in which individuals with the highest skill make positive tax payments to either country. In Section 4, we show that it is impossible for the lowest skilled to receive a subsidy from either country in equilibrium. We establish the existence of an equilibrium for our model in Section 5 by showing that the laissez-faire solution is a Nash equilibrium. We also describe a class of equilibria in which the highest skilled individuals receive net transfers that are funded by taxes imposed on lower skilled individuals. In Section 6, we offer some concluding remarks.

\section{The Model}

There are two countries, $A$ and $B$, who have access to the same constant returns to scale production technology that can be used to transform a single input, effective labor, into a single output. Units of these goods are normalized so that one unit of effective labor produces one unit of output. There are $n \geq 2$ types of individuals who differ in their

\footnotetext{
${ }^{4}$ See also the recent articles by Krause (2007) and Simula and Trannoy (2006), both of which deal with nonlinear taxation.
} 
labor productivities. An individual's labor productivity is the same in both countries. A type $i$ individual has productivity $w_{i}$; that is, a unit of labor time supplied by such an individual is equivalent to $w_{i}$ units of effective labor. Thus, by supplying $l_{i}$ units of labor, an individual of type $i$ produces $y_{i}=w_{i} l_{i}$ units of output. The production sector is perfectly competitive and, hence, the wage rate of an individual of type $i$ equals his productivity $w_{i}$ and his pretax income equals the amount of output $y_{i}$ that he produces. Types are ordered so that $w_{1}<w_{2}<\cdots<w_{n}$. The total number of individuals of type $i$ is $N_{i}>0$. The distribution of these types is common knowledge.

Every individual has the same preferences over consumption $c$ and hours of work $l$. These preferences are represented by the cardinally significant utility function $u(c, l)$. The function $u(\cdot)$ is strictly increasing in $c$, strictly decreasing in $l$, strictly concave, and twice continuously differentiable. For an individual with labor productivity $w$, his utility expressed in terms of observable variables is given by

$$
v(c, y ; w)=u\left(c, \frac{y}{w}\right) .
$$

These preferences satisfy the usual single-crossing property. In $(y, c)$-space, each person's indifference curves are upward sloping, with the slope increasing along an indifference curve as $y$ increases. Furthermore, the slope of the indifference curve through $(y, c)$ decreases with an increase in $w$.

Utility is not directly affected by location; that is, holding consumption and labor supply fixed, individuals are indifferent between country of residence. Thus, countries possess no country-specific amenities that any individual might find attractive and that would therefore introduce frictions to labor mobility based on residential attachments. We also assume that no expenditure of resources is required to change country of residence. Together, these features of our model imply that labor is perfectly mobile. As a consequence, it does not matter whether we regard individuals as having an initial country of residence or if we treat them as being initially stateless. For concreteness, we make the latter assumption, so an individual acquires his nationality by his choice of residence.

The government in each country has the authority to levy taxes on its residents for the purpose of redistributing income among them. Neither government can observe the labor productivity or the hours worked of any individual, but each of them can observe who resides within its borders and what each resident's pretax income is. Accordingly, taxes are based on labor income. The governments simultaneously and independently announce type-independent income tax schedules, $\tau^{A}(\cdot)$ and $\tau^{B}(\cdot)$, where $\tau^{j}(y)$ is the tax paid by a resident of country $j, j=A, B$, whose income is $y$. Each individual then chooses where to reside and how much labor to supply taking these tax schedules as given. These choices determine the amount of tax he pays, the government to which he remits these payments, and his after-tax income. Because there are no resource costs associated with the choice of residence, his consumption of the single output good equals his after-tax income. The number of individuals of type $i$ choosing to reside in country $j$ is $N_{i}^{j}$, where $N_{i}^{A}+N_{i}^{B}=N_{i}$ for all $i$. 
Because labor is freely mobile and the tax schedules are anonymous, with the amount of tax paid only a function of an individual's own income, we can equivalently think of country $j$ as directly offering consumption $c_{i}^{j}$ and income $y_{i}^{j}$ to a type $i$ individual subject to a set of self-selection constraints. ${ }^{5}$ See, for example, Guesnerie and Seade (1982). These self-selection constraints only apply to income-consumption bundles that are actually chosen by some individual. Thus, the allocations offered by the two countries must satisfy

$v\left(c_{i}^{j}, y_{i}^{j} ; w_{i}\right) \geq v\left(c_{h}^{k}, y_{h}^{k} ; w_{i}\right)$ for all $j, k=A, B$ and all $h, i=1,2, \ldots, n$ such that $N_{i}^{j}>0$.

We assume that if $v\left(c_{i}^{j}, y_{i}^{j} ; w_{i}\right)=v\left(c_{h}^{k}, y_{h}^{k} ; w_{i}\right)$ with $h \neq i$, then an individual of type $i$ chooses the bundle intended for his type; i.e., he chooses $\left(c_{i}^{j}, y_{i}^{j}\right)$. This assumption is standard in finite population optimal nonlinear income tax models when there is no mobility. We refer to $a^{j}=\left(c_{1}^{j}, y_{1}^{j}, \ldots, c_{n}^{j}, y_{n}^{j}\right)$ as the allocation offered by country $j$.

An immediate implication of the self-selection constraints is that if individuals of the same type reside in both countries, then they must receive the same utility regardless of where they live. Furthermore, within a country, (i) consumption and income are nondecreasing in type and two types have the same income if and only if they have the same consumption, in which case they are said to be bunched, and (ii) utility is increasing in type.

An individual of type $i$ who resides in country $j$ pays

$$
T_{i}^{j}=y_{i}^{j}-c_{i}^{j}, \quad j=A, B, i=1,2, \ldots, n,
$$

in taxes to government $j$. If $T_{i}^{j}$ is negative, then this individual receives a transfer of $\left|T_{i}^{j}\right|$. The tax schedule $\tau^{j}(\cdot)$ that supports the allocation offered by country $j$ has the property that $\left(c_{i}^{j}, y_{i}^{j}\right)$ maximizes a type $i$ individual's utility subject to $\tau^{j}(\cdot)$ for all $i$ including $i$ for which $N_{i}^{j}=0$.

Each government wants to maximize the average utility of its residents. Formally, social welfare in country $j$ is given by

$$
W\left(u_{1}^{j}, u_{2}^{j}, \ldots, u_{n}^{j} ; N_{1}^{j}, N_{2}^{j}, \ldots, N_{n}^{j}\right)=\left\{\begin{array}{cc}
\frac{\sum_{i=1}^{n} N_{i}^{j} u_{i}^{j}}{\sum_{i=1}^{n} N_{i}^{j}} & \text { if } \sum_{i=1}^{n} N_{i}^{j}>0 \\
-\infty & \text { if } \sum_{i=1}^{n} N_{i}^{j}=0
\end{array}, \quad j=A, B\right.
$$

where $u_{i}^{j}$ is the utility of a type $i$ individual residing in country $j .{ }^{6}$ With this welfare criterion, the individuals whom a government cares for are exactly those individuals

\footnotetext{
${ }^{5}$ Our restrictions on the tax schedules conform to the practice in the optimal tax literature, rather than in the mechanism design literature, which typically places no a priori restrictions on the admissible mechanisms. Note that we are not appealing to the revelation principle here, which, as discussed in Martimort and Stole (2002), is problematic in multi-principal settings.

${ }^{6}$ If nobody of type $i$ resides in country $j$, then the value of $u_{i}^{j}$ can be chosen arbitrarily. Because all individuals of the same type obtain the same utility when the self-selection constraints are satisfied, it is only necessary to consider the number of individuals who reside in a country and their common level of utility.
} 
whom it taxes. Moreover, individuals are sufficiently footloose that there is no meaningful distinction between residents and citizens of the type considered by Simula and Trannoy (2006) that might justify differential tax treatment of them. ${ }^{7}$

The average utilitarian form of each government's objective gives rise to an important trade-off. On the one hand, if individuals were not mobile, an average utilitarian government would want to depart from the laissez-faire outcome by redistributing income from more highly skilled to less highly skilled workers, provided that the natural conditions on individual utility functions described by Dixit and Seade (1979) are satisfied. The desirabilty of engaging in such redistribution is present whenever any of the adjacent downward self-selection constraints do not bind. On the other hand, because the selfselection constraints imply that utilities are nondecreasing in type, governments have an incentive to attract the most highly skilled workers so as to increase the average utility of their residents. Thus, each government faces a tension between the desire to redistribute resources from higher skill types to lower skill types and the possibility that, if taken too far, this redistribution might lead to exit by higher skill types and a concomitant decrease in average utility. As emphasized by Cremer and Pestieau (2004) and Wilson (2006), this tension plays a fundamental role in the literature on redistributive taxation in the presence of mobile labor.

In addition to taking acount of the self-selection constraints, each government must ensure that it has sufficient resources to carry out the redistribution that is required to implement the labor-consumption choices of those individuals who choose to reside in its county. Formally, the allocation of consumption and pretax income (effective labor) offered by country $j$ must satisfy the following materials balance constraint:

$$
\sum_{i=1}^{n} N_{i}^{j} c_{i}^{j} \leq \sum_{i=1}^{n} N_{i}^{j} y_{i}^{j}, \quad j=A, B .
$$

By Walras' Law, this feasibility constraint is equivalent to requiring that the net tax revenue be nonnegative:

$$
\sum_{i=1}^{n} N_{i}^{j} T_{i}^{j} \geq 0
$$

A pair of allocations $a^{A}$ and $a^{B}$ is a Nash equilibrium if neither government has an incentive to change its allocation given the allocation offered by the other country. ${ }^{8}$ When

\footnotetext{
${ }^{7}$ The benefits provided by citizenship introduce frictions to mobility that have been ruled out by our assumption that labor is freely mobile. In a model with mobility costs, it would be natural to consider the possibility of subjecting residents and citizens to different tax schedules. Actual practice in this regard varies from country to country. For example, a citizen of the United States is subject to U.S. tax on his worldwide income regardless of his country of residence, whereas a Canadian citizen is not liable for tax in Canada if he resides elsewhere. For discussions of the relative merits of different proposals about who should count in a country's social welfare function, who it should tax, and how it should compute its income tax base, see Mirrlees (1982), Cremer and Pestieau (2004), and Wilson (2006).

${ }^{8}$ Equivalently, a pair of tax schedules $\tau^{A}(\cdot)$ and $\tau^{B}(\cdot)$ is a Nash equilibrium if neither government has an incentive to change its tax schedule given the tax schedule offered by the other country.
} 
deciding on the potential benefits of revising the allocation it offers, a government anticipates the income-consumption and locational responses of individuals to these changes. It is possible that the allocation announced by one country, perhaps one that is obtained by deviating from a candidate equilibrium, results in a set of individual residential decisions that leave the other government with a budget deficit. Indeed, whenever a government, say in country $A$, considers modifying the allocation it offers for the express purpose of attracting individuals who pay positive taxes in the other country without otherwise altering the distribution of the other types of individuals across countries, the policy change in question results in a loss of revenue in the other country. Imposing the restriction that country $B$ 's revenue constraint be satisfied after $A$ changes its offer is inconsistent with the notion of Nash equilibrium, for such a restriction requires, contrary to the usual Nash conjectures, that country $A$ foresee a budget-balancing response by country $B .{ }^{9}$ Note, however, that the revenue constraints of both governments are satisfied in a Nash equilibrium.

\section{The Impossibility of Taxing the Highest Skilled}

A government engaging in redistributive taxation has an incentive to attract highly skilled individuals from the other country. In single-country formulations of the optimal nonlinear income tax problem, the tax paid is nondecreasing in the skill level if, as is typically the case, the government wants to redistribute resources towards the lower skilled individuals. ${ }^{10}$ The more skilled individuals pay taxes that help finance transfers to individuals with low skills. This observation suggests that a country might wish to attract highly skilled individuals in order to make it easier to finance its redistributive goals. Moreover, because utility is increasing in the skill level, a government with an average utilitarian objective function would want to attract these individuals for the direct contribution they make to social welfare. The ability to announce a fully nonlinear tax schedule provides governments with a powerful tool to compete for the most highly skilled workers. Each government can design its tax schedule in such a way as to offer income-consumption pairs targeted directly at individuals of type $n$. Because these individuals are completely mobile, either government can attract all individuals of type $n$ by offering them a utility level slightly above that offered by its competitor. Therefore, the governments engage in Bertrand-type undercutting of the taxes paid by the highest skilled individuals. We show in Proposition 1 below that this intense competition makes it impossible for either government to raise any tax revenue from these individuals.

The following lemma is useful in developing the argument for Proposition 1. It shows that it is not possible to have a Nash equilibrium in the tax competition game that results in individuals of type $n$ living in and paying positive taxes in each country.

\footnotetext{
${ }^{9}$ Piaser (2007) also employs this notion of equilibrium in his study of income tax competition.

${ }^{10}$ This result is a direct consequence of combining Proposition 6 in Guesnerie and Seade (1982) with Proposition 1 in Brito, Hamilton, Slutsky, and Stiglitz (1990).
} 
Lemma 1. There does not exist a Nash equilibrium in which $T_{n}^{A}>0, T_{n}^{B}>0, N_{n}^{A}>0$, and $N_{n}^{B}>0$.

Proof. Suppose, by way of contradiction, that there does exist a Nash equilibrium with $T_{n}^{A}>0$ and $T_{n}^{B}>0$ in which $N_{n}^{A}>0$ and $N_{n}^{B}>0$. For all $i$ and $j$, let $x_{i}^{j}=\left(y_{i}^{j}, c_{i}^{j}\right)$ be the bundle offered by country $j$ to a type $i$ individual. It follows from the self-selection constraints (2.2) that $x_{n}^{A}$ and $x_{n}^{B}$ are on the same indifference curve.

We first show that $x_{n}^{A}=x_{n}^{B}$. Without loss of generality, suppose that $x_{n}^{B} \gg x_{n}^{A} \cdot{ }^{11}$ By self-selection and single-crossing, all individuals of a type other than $n$ strictly prefer the bundle designed for them in the country they are currently residing to $x_{n}^{B}$. Now suppose that the government of country $B$ increases $c_{n}^{B}$ by $\varepsilon>0$ holding all other components of the allocation on offer fixed. By choosing $\varepsilon$ to be sufficiently small, no individual of types 1 through $n-1$ prefers the modified bundle for type $n$. However, all individuals of type $n$ strictly prefer the new bundle offered to them to what they receive in the candidate equilibrium. Hence, all individuals of type $n$ initially residing in country $A$ now move to country $B$. These new residents pay positive taxes. By choosing $\varepsilon$ sufficiently small, this new tax revenue exceeds the marginal loss in revenue from the type $n$ individuals residing in country $B$ prior to the tax reform. Thus, the new allocation satisfies the government budget constraint (2.6) in country $B$. Moreover, by self-selection, individuals of type $n$ have the highest utility level. Therefore, adding more individuals of type $n$ to country $B$ increases average utility in country $B$. Thus, the modified allocation constitutes a better reply for country $B$ to country $A$ 's allocation on offer than does the allocation country $B$ offers in the candidate equilibrium, contradicting our supposition that the initial allocations constitute a Nash equilibrium. Hence, it must be the case that $x_{n}^{A}=x_{n}^{B}$.

Starting with the allocations on offer in the candidate equilibrium, we now show how country $A$ can modify its proposed allocation so as to increase average utility in its country while at the same time satisfying all of the constraints that it faces. In the candidate equilibrium, the income-consumption bundles offered by either country to individuals of types 1 through $n-1$ must lie must lie on or below both the type $n$ and type $n-1$ indifference curves through $x_{n}^{A}=x_{n}^{B}$. Suppose that country $A$ replaces $x_{n}^{A}$ with a bundle $\tilde{x}_{n}^{A} \gg x_{n}^{A}$ lying above the type $n$ indifference curve through $x_{n}^{A}$ but below the type $n-1$ indifference curve through $x_{n}^{A}$, as illustrated in Figure 1. All individuals of type $i \neq n$ strictly prefer their initial bundles to $\tilde{x}_{n}^{A}$. The bundle $\tilde{x}_{n}^{A}$ increases the utility of type $n$ individuals residing in country $A$ and entices those type $n$ individuals residing in country $B$ to move to country $A$, thereby increasing average utility in country $A$. Let $\tilde{T}_{n}^{A}$ be the tax payment associated with $\tilde{x}_{n}^{A}$. If $\tilde{T}_{n}^{A} \geq T_{n}^{A}$, the new allocation also satisfies country $A$ 's revenue constraint. Thus, the allocation initially offered by country $A$ is not a best reply to the one offered by country $B$. If $\tilde{T}_{n}^{A}<T_{n}^{A}$, then country $A$ 's revenue

\footnotetext{
${ }^{11}$ Because indifference curves in $(y, c)$-space are increasing, we must have $x_{n}^{B} \gg x_{n}^{A}$ or $x_{n}^{A} \gg x_{n}^{B}$ if $x_{n}^{A} \neq x_{n}^{B}$.
} 


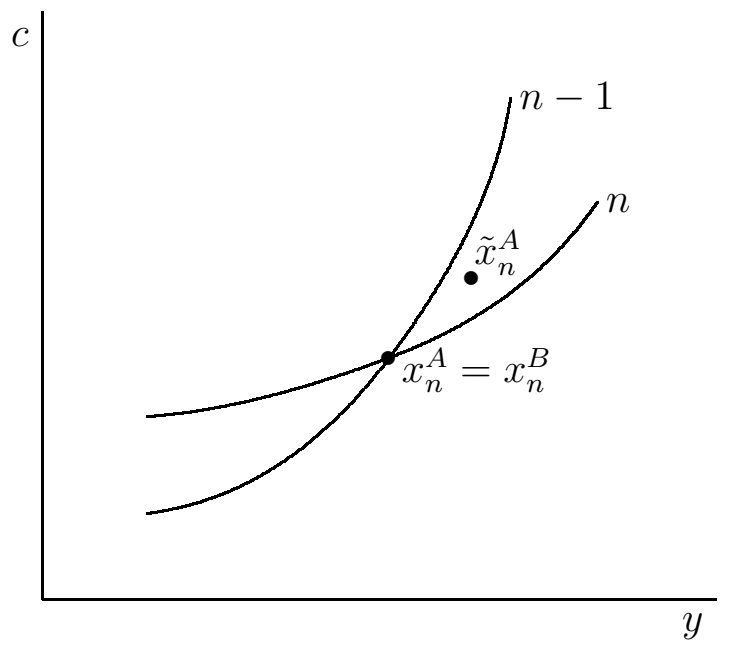

Figure 1: Reforming country A's tax schedule to attract the most highly skilled

constraint is satisfied provided that

$$
N_{n}^{A}\left(T_{n}^{A}-\tilde{T}_{n}^{A}\right) \leq N_{n}^{B} \tilde{T}_{n}^{A}
$$

which is equivalent to

$$
\left(\frac{N_{n}^{A}}{N_{n}^{A}+N_{n}^{B}}\right) \leq \frac{\tilde{T}_{n}^{A}}{T_{n}^{A}} .
$$

By choosing $\tilde{x}_{n}^{A}$ sufficiently close to $x_{n}^{A}, \tilde{T}_{n}^{A}$ can be made arbitrarily close to $T_{n}^{A}$. For such an $\tilde{x}_{n}^{A}$, the inequality in (3.2) is satisfied and, hence, $\tilde{x}_{n}^{A}$ is feasible.

Having shown that the allocation offered by country $A$ in the candidate equilibrium is not a best reply to the one offered by country $B$, we conclude that no such equilibrium exists. That is, there does exist a Nash equilibrium with $T_{n}^{A}>0$ and $T_{n}^{B}>0$ in which $N_{n}^{A}>0$ and $N_{n}^{B}>0$.

Even though a country must collect less tax revenue per person from its most highly skilled residents in order to attract more of this type of individual to its country, the additional tax revenue it receives from the newcomers can more than compensate for this loss. The small losses at the intensive margin are of marginal significance compared to the revenue gains at the extensive margin. Hence, either country can feasibly raid the other country for its most highly skilled workers. Because these are the individuals with the highest utilities, governments that want to maximize the average utility of their residents have an incentive to engage in such self-defeating competition.

If, contrary to the hypotheses of Lemma 1, one of the two countries has all of the individuals of type $n$ living inside its borders and it extracts positive tax revenue from them, then the other country has an incentive to redesign its tax schedule so as to induce 
these individuals to move. As the proof of Proposition 1 demonstrates, it can do so without having to modify the taxes paid by its other residents and without running a budget deficit. Thus, in equilibrium, no country can levy a tax on the most highly skilled individuals.

Proposition 1. There does not exist a Nash equilibrium in which either (a) $T_{n}^{A}>0$ and $N_{n}^{A}>0$ or (b) $T_{n}^{B}>0$ and $N_{n}^{B}>0$.

Proof. Without loss of generality, we show that no equilibrium exists with $T_{n}^{A}>0$ and $N_{n}^{A}>0$. To that end, suppose, by way of contradiction, that such an equilibrium exists. For all $i$ and $j$, let $x_{i}^{j}=\left(y_{i}^{j}, c_{i}^{j}\right)$ be the bundle offered by country $j$ to a type $i$ individual. There are two cases to consider: either $N_{n}^{B}=0$ or $N_{n}^{B}>0$. In each case, a single country changes the income-consumption bundle designed for the most highly skilled individuals, with no change in the rest of the allocation that is being offered. This new bundle is chosen so that the only individuals who move or receive a different bundle are those of type $n$.

If $N_{n}^{B}=0$, then country $B$ can offer a bundle $\tilde{x}_{n}^{B}$ above the type $n$ indifference curve through $x_{n}^{A}$ but below the $n-1$ type indifference curve through $x_{n}^{A}$ that is sufficiently close to $x_{n}^{A}$ so that the resulting tax revenue $\tilde{T}_{n}^{B}$ from an individual of type $n$ is positive. All individuals of this type will move from country $A$ to country $B$, increasing average utility in country $B$ while at the same time generating a budget surplus.

If $N_{n}^{B}>0$, then $x_{n}^{A}$ and $x_{n}^{B}$ are on the same indifference curve. Country $A$ can then offer a bundle $\tilde{x}_{n}^{A}$ just like the one offered in the proof of Lemma 1 to break the candidate equilibrium.

The reasoning used to establish Proposition 1 does not extend to individuals of any type other than $n$ for two reasons. First, there is no guarantee that attracting individuals of any other type results in an increase in a country's average utility. Second, any attempt to adjust $x_{i}^{A}$ for $i \neq n$ in a manner analogous to the adjustment made to $x_{n}^{A}$ in the proof of Lemma 1 may well violate a self-selection constraint by providing individuals of type $i+1$ an incentive to pretend to be of type $i$.

\section{The Impossibility of Subsidizing the Least Skilled}

In the absence of labor mobility between countries, a government with redistributive goals transfers resources to the lowest-skilled individuals, who pay a negative tax. However, when the self-selection constraints are satisfied, these individuals have the lowest utilities post transfer. As a consequence, if labor is mobile, there are strong incentives to induce the lowest skilled to emigrate. If a country succeeds in inducing its poorest residents to move without otherwise affecting who resides within its borders and without changing what it offers to the other types of individuals, then it will have increased the average utility of the residents who remain. Furthermore, it will run a budget surplus, and it may be possible to use this surplus to further increase the utilities of the remaining residents. 
However, simply reducing the subsidy offered to the lowest skilled by reducing the consumption offered to them may not lead to any mobility because what is offered to these individuals in the other country may be so unattractive that none of the lowest skilled individuals want to locate there. Nevertheless, in Proposition 2 below, we show that the competition between the two countries is sufficiently intense that no type 1 individual is subsidized in equilibrium. Thus, the tax competition thwarts the redistributive goals of both governments.

If individuals of type 1 live in both countries, they obtain the same utility. When this is the case, any country offering the lowest skilled a subsidy can induce them to move by offering them lower consumption. Therefore, there is no Nash equilibrium in the tax competition game that results in individuals of type 1 living in both countries, with at least one of these countries subsidizing them.

Lemma 2. There does not exist a Nash equilibrium in which $N_{1}^{A}>0, N_{1}^{B}>0$, and either (a) $T_{1}^{A}<0$ or (b) $T_{1}^{B}<0$.

Proof. Suppose, by way of contradiction, that such a Nash equilibrium exists. For all $i$ and $j$, let $x_{i}^{j}=\left(y_{i}^{j}, c_{i}^{j}\right)$ be the bundle offered to a type $i$ individual by country $j$. Without loss of generality, we assume that case (a) applies. Thus, $T_{1}^{A}<0$, which implies that $c_{i}^{A}>0$. In order for country $A$ 's revenue constraint to be satisfied, it must be raising a positive tax revenue from types 2 through $n$. By the self-selection constraints $(2.2), x_{1}^{A}$ and $x_{1}^{B}$ are on the same indifference curve.

Suppose that the government of country $A$ decreases $c_{i}^{A}$ by $\varepsilon>0$, with $\varepsilon$ chosen so that $c_{i}^{A}-\varepsilon \geq 0$, leaving all of the other components of the allocation offered by country $A$ unchanged. The individuals of type 1 all strictly prefer $x_{1}^{B}$ to the new offer of country $A$ and weakly prefer $x_{1}^{B}$ to any other bundle that is available, and so locate in country $B{ }^{12}$ No other type of individual is affected by the change in the allocation offered by country $A$. Because $T_{1}^{A}<0$ and $N_{1}^{A}>0$, the exit of individuals of type 1 from country $A$ leave it with a budget surplus. By self-selection, these individuals have the lowest utility. Therefore, when they move, country A's average utility increases. Hence, the initial allocations offered by the two countries are not a Nash equilibrium.

If all of the type 1 individuals live in one country, say country $A$, it may be impossible to induce them to relocate without violating one of the constraints. However, if they are being subsidized, it is possible for one of the countries to attract everyone who is not of type 1 from the other country in such a way as to increase its average utility. If the average utility of all but the lowest type is no smaller in country $A$ than in country $B$, then country $B$ can increase its average utility by inducing these types to immigrate without also attacting country $A$ 's type 1 residents. These immigrants generated the resources needed to subsidize the lowest skilled in country $A$. These resources can be

\footnotetext{
${ }^{12}$ It is possible that the type 1 individuals are indifferent between $x_{1}^{B}$ and $x_{2}^{A}$. By assumption, they choose $x_{1}^{B}$, the bundle designed for their type. This is the only place in any of our proofs where this assumption is used.
} 
used instead by country $B$ to increase the utility of everyone who is not of type 1 . If, however, the average utility of all but the lowest type is smaller in country $A$ than in country $B$, then country $A$ has an incentive to attract country $B$ 's residents. If country $B$ 's revenue constraint held with equality, these immigrants bring no budget surplus with them. Nevertheless, the resources needed to improve the welfare of these types can be generated either by inducing the lowest skilled in country $A$ to emigrate or by marginally decreasing their consumption, depending on whether the lowest skilled are indifferent between what they receive in country $A$ and what country $B$ offers them or not. In view of Lemma 2, it then follows that there is no Nash equilibrium in which the lowest skilled receive a subsidy.

Proposition 2. There does not exist a Nash equilibrium in which either (a) $T_{1}^{A}<0$ and $N_{1}^{A}>0$ or (b) $T_{1}^{B}<0$ and $N_{1}^{B}>0$.

Proof. On the contrary, suppose that such a Nash equilibrium exists. Without loss of generality, we assume that case (a) applies. By Lemma 2, it follows that $N_{1}^{B}=0$.

We first show that there must be at least one individual living in country $B$. Suppose that this is not the case and, thus, that the level of social welfare in country $B$ is $-\infty$. In order for country $A$ to satisfy its revenue constraint, there must be some type $k \geq 2$ for which $T_{k}^{A}>0$. Let $\hat{x}_{k}=\left(\hat{c}_{k}, \hat{y}_{k}\right)$ be the bundle that maximizes type $k$ utility subject to the constraint that $c_{k}=y_{k}$. If country $B$ offers the allocation in which $\hat{x}_{k}^{B}=\hat{x}_{k}$ and $\hat{x}_{j}^{B}=(0,0)$ for all $j \neq k$, then all individuals of type $k$ relocate to country $B$, as does any other individual whose initial bundle is dominated by $(0,0)$. In this allocation, the residents of country $B$ simply consume what they produce, so country $B$ 's revenue constraint holds with equality. Furthermore, all of the self-selection constraints are satisfied. The average utility in country $B$ is now nonnegative and, hence, it is not a Nash equilibrium to have nobody live in country $B$.

For all $i$ and $j$, let $x_{i}^{j}=\left(y_{i}^{j}, c_{i}^{j}\right)$ be the bundle offered to a type $i$ individual by country $j$ in the candidate equilibrium. If type $i$ individuals live in both countries, by the selfselection constraints, they must receive the same utility. Thus, we can let $u_{i}$ denote the utility a type $i$ individual obtains when he chooses from this menu of options, regardless of whether individuals of this type reside in both countries. We consider two cases.

Case 1. Suppose that the average utility of the $(n-1)$-highest types is no smaller in country $A$ than in country $B$. That is,

$$
\frac{\sum_{i=2}^{n} N_{i}^{A} u_{i}}{\sum_{i=2}^{n} N_{i}^{A}} \geq \frac{\sum_{i=2}^{n} N_{i}^{B} u_{i}}{\sum_{i=2}^{n} N_{i}^{B}} .
$$

We show that it is possible for country $B$ to increase its average utility by attracting all of the residents of country $A$ except for the lowest skilled.

Country $B$ constructs a new offer in a series of steps as follows. Let

$$
\tilde{x}_{i}^{B}=\frac{N_{i}^{A} x_{i}^{A}+N_{i}^{B} x_{i}^{B}}{N_{i}^{A}+N_{i}^{B}}, \quad i=2, \ldots, n .
$$


If $N_{i}^{A}=0\left(\right.$ resp. $\left.N_{i}^{B}=0\right)$, then $\tilde{x}_{i}^{B}=x_{i}^{B}$ (resp. $\tilde{x}_{i}^{B}=x_{i}^{A}$ ). Otherwise, $\tilde{x}_{i}^{B}$ is a weighted sum of the initial bundles chosen by the type $i$ individuals, with the weights given by the initial population shares of these individuals in the two countries. By the strict concavity of the utility function $v$,

$$
v\left(\tilde{x}_{i}^{B} ; w_{i}\right) \geq u_{i}, \quad i=2, \ldots, n,
$$

with a strict equality for any $i$ for which $N_{i}^{A}>0, N_{i}^{B}>0$, and $x_{i}^{A} \neq x_{i}^{B}$. Now choose $\bar{c}_{i}$ so that

$$
v\left(\bar{c}_{i}^{B}, \tilde{y}_{i}^{B} ; w_{i}\right)=u_{i}, \quad i=2, \ldots, n .
$$

Note that $\bar{c}_{i} \leq \tilde{c}_{i}^{B}$ for all $i \geq 2$. Let $\bar{x}_{i}^{B}=\left(\bar{c}_{i}^{B}, \tilde{y}_{i}^{B}\right)$ for $i \geq 2$ and $\bar{x}_{1}^{B}=x_{1}^{B}$.

For any initial resident of country $A$ of type $i \geq 2$, it is a matter of indifference whether to choose $x_{i}^{A}$ or $\bar{x}_{i}^{B}$. Later, we shall provide an positive incentive for these individuals to move, but for now we simply show that if they all relocate, then country $B$ runs a budget surplus and all of the self-selection constraints are satisfied. More concretely, suppose that all individuals of type $i \geq 2$ choose $\bar{x}_{i}^{B}$ and the individuals of type 1 keep their initial bundles and do not relocate.

We first determine the revenue implications of having all individuals of type $i \geq 2$ choose $\tilde{x}_{i}^{B}$. In this case, country $B$ 's tax revenue from all types is the sum of its initial tax revenue and the tax revenue raised from types $i \geq 2$ in country $A$ in the candidate equilibrium. The former is nonnegative and the latter is positive. If the individuals of type $i \geq 2$ instead choose $\bar{x}_{i}^{B}$, because $\bar{c}_{i} \leq \tilde{c}_{i}^{B}$ for all $i \geq 2$, it follows that country $B$ runs a budget surplus. ${ }^{13}$

By construction, all individuals are indifferent between the bundles they receive in the candidate equilibrium and in the alternative situation that we are considering. Furthermore, the only individuals who receive a new bundle are individuals of type $i \geq 2$ for whom $N_{i}^{A}>0, N_{i}^{B}>0$, and $x_{i}^{A} \neq x_{i}^{B}$. For such an individual, $\bar{x}_{i}^{B}$ lies between $x_{i}^{A}$ and $x_{i}^{B}$ on type $i$ 's initial indifference curve. Because all of the self-selection constraints are satisfied in the candidate equilibrium, by single-crossing, they are also satisfied when country $B$ offers the allocation $\bar{x}^{B}=\left(x_{1}^{B}, \ldots, x_{n}^{B}\right)$.

We now modify the $\bar{x}_{i}^{B}$ bundles so that all individuals of types $i \geq 2$ strictly prefer to locate in country $B$ and so that no self-selection constraint for individuals of different types binds. Let $\hat{x}_{1}^{B}=\bar{x}_{1}^{B}=x_{1}^{B}$. For $i \geq 2$, let $\hat{x}_{i}^{B}=\bar{x}_{i}^{B}+\left(\varepsilon_{i}^{1}, \varepsilon_{i}^{2}\right)$ with $\left(\varepsilon_{i}^{1}, \varepsilon_{i}^{2}\right) \gg(0,0)$ chosen so that $v\left(\hat{x}_{i}^{B}, w_{i}\right)>v\left(\bar{x}_{i}^{B}, w_{i}\right)$ and $v\left(\hat{x}_{i-1}^{B}, w_{i-1}\right)>v\left(\hat{x}_{i}^{B}, w_{i-1}\right)$ for all $i \geq 2$ and $v\left(\hat{x}_{i+1}^{B}, w_{i+1}\right)>v\left(\hat{x}_{i}^{B}, w_{i+1}\right)$ for all $i \leq n-1$. Because the self-selection constraints are satisfied before this modification, by single-crossing, this construction is possible with arbitrarily small values for $\varepsilon_{i}^{1}$ and $\varepsilon_{i}^{2}$. If country $B$ offers the $\hat{x}_{i}^{B}$ bundles holding country $A$ 's offered allocation fixed, the type 1 individuals retain their initial bundles and do not move, whereas everyone else locates in country $B$. Furthermore, all of the self-selection constraints are satisfied. Because country $B$ has a budget surplus if all individuals of

\footnotetext{
${ }^{13}$ A more formal argument for this conclusion using Jensen's inequality can be provided by adapting the proof of Lemma 4 in Blackorby, Brett, and Cebreiro (2007).
} 
type $i \geq 2$ reside there and receive the bundle $\bar{x}_{i}^{B}$, by choosing the values of $\varepsilon_{i}^{1}$ and $\varepsilon_{i}^{2}$ sufficiently small, its revenue constraint will be satisfied.

It remains to show that the average utility in country $B$ has increased. By the continuity and monotonicity of the social welfare function, there exist $\bar{u}^{A}$ and $\bar{u}^{B}$ such that

$$
\bar{u}^{j}=\frac{\sum_{i=2}^{n} N_{i}^{j} \bar{u}^{j}}{\sum_{i=2}^{n} N_{i}^{j}}=\frac{\sum_{i=2}^{n} N_{i}^{j} u_{i}}{\sum_{i=2}^{n} N_{i}^{j}}, \quad j=A, B .
$$

By (4.1), $\bar{u}^{A} \geq \bar{u}^{B}$. Let $\hat{u}_{i}$ be the utility a type $i$ individual obtains when country $B$ offers the $\hat{x}_{i}^{B}$ bundles and country $A$ offers the $x_{i}^{A}$ bundles. Because nobody of type 1 lives in country $B$, the average utility in country $B$ after it modifies its offered allocation is $\left(\sum_{i=2}^{n} N_{i}^{A} \hat{u}_{i}+\sum_{i=2}^{n} N_{i}^{B} \hat{u}_{i}\right) /\left(\sum_{i=2}^{n}\left(N_{i}^{A}+N_{i}^{B}\right)\right)$. We have

$$
\begin{aligned}
\frac{\sum_{i=2}^{n} N_{i}^{A} \hat{u}_{i}+\sum_{i=2}^{n} N_{i}^{B} \hat{u}_{i}}{\sum_{i=2}^{n}\left(N_{i}^{A}+N_{i}^{B}\right)} & >\frac{\sum_{i=2}^{n} N_{i}^{A} u_{i}+\sum_{i=2}^{n} N_{i}^{B} u_{i}}{\sum_{i=2}^{n}\left(N_{i}^{A}+N_{i}^{B}\right)} \\
& =\frac{\sum_{i=2}^{n} N_{i}^{A} \bar{u}^{A}+\sum_{i=2}^{n} N_{i}^{B} \bar{u}^{B}}{\sum_{i=2}^{n}\left(N_{i}^{A}+N_{i}^{B}\right)} \\
& \geq \frac{\sum_{i=2}^{n} N_{i}^{A} \bar{u}^{B}+\sum_{i=2}^{n} N_{i}^{B} \bar{u}^{B}}{\sum_{i=2}^{n}\left(N_{i}^{A}+N_{i}^{B}\right)} \\
& =\bar{u}^{B},
\end{aligned}
$$

where the first inequality in (4.6) follows from the fact that $\hat{u}_{i}>u_{i}$ for all $i \geq 2$, the first equality follows from (4.5), and the second inequality follows from the fact that $\bar{u}^{A} \geq \bar{u}^{B}$. Thus, the average utility in country $B$ increases when it offers the $\hat{x}_{i}^{B}$ bundles instead of the $x_{i}^{B}$ bundles.

Case 2. Now suppose that the average utility of the $(n-1)$-highest types is smaller in country $A$ than in country $B$. That is,

$$
\frac{\sum_{i=2}^{n} N_{i}^{A} u_{i}}{\sum_{i=2}^{n} N_{i}^{A}}<\frac{\sum_{i=2}^{n} N_{i}^{B} u_{i}}{\sum_{i=2}^{n} N_{i}^{B}} .
$$

We show that it is possible for country $A$ to increase its average utility by attracting all of the residents of country $B$.

If we simply reverse the roles of countries $A$ and $B$ in the proof of Case 1 , when the residents of country $B$ relocate and choose the $\tilde{x}_{i}^{A}$ bundles (in obvious notation) in the first step of constructing country $A$ 's new offer, they bring no budget surplus with them if country $B$ exactly balances its budget in the candidate equilibrium. If, furthermore, $x_{i}^{A}=x_{i}^{B}$ for all $i$ for which there are initially residents in both countries, then $\bar{x}_{i}^{A}=\tilde{x}_{i}^{A}$ for all $i \geq 2$, so no budget surplus is generated in the second step of constructing country $A$ 's new offer either. As a consequence, when country $A$ offers the $\hat{x}_{i}^{A}$ bundles, it may not satisfy its revenue constraint. It is therefore necessary to further modify country $A$ 's proposed allocation. 
Because the inequality in (4.7) is strict (and, hence, a strict inequality is used instead of a weak inequality in the analogue of (4.6)), if the residents of country $B$ relocate and choose the $\bar{x}_{i}^{A}$ bundles, then reasoning as in the proof of Case 1, we can show that all of the self-selection contraints are satisfied, country $A$ satisfies its revenue constraint, and it has strictly increased the average utility of its residents of types $i \geq 2$. Country $A$ further increases the average utility of these residents when it replaces the $\bar{x}_{i}^{A}$ bundles with the $\hat{x}_{i}^{A}$ bundles, no matter how small the adjustments to the allocation are in this step. Because utility is increasing in type and because $\hat{u}_{1}=u_{1}$, it then follows that the average utility in country $A$ (including its type 1 residents) increases when it offers the $\hat{x}_{i}^{A}$ bundles instead of the $x_{i}^{A}$ bundles because no type 1 individual moves.

When country $A$ makes these adjustments, none of the self-selection constraints that pertain to different types bind. If type 1 individuals strictly prefer $\hat{x}_{i}^{A}=x_{1}^{A}$ to $x_{1}^{B}$, it is possible to restore budget feasibility by marginally decreasing $\hat{c}_{1}^{A}=c_{1}^{A}$ without violating any self-selection constraints and at the same time not reducing country $A$ 's average utility below what it is in the candidate equilibrium provided that the $\varepsilon_{i}^{1}$ and $\varepsilon_{i}^{2}$ are chosen sufficiently close to 0 . However, it is also possible that all type 1 individuals locate in country $A$ in the candidate equilibrium even though they would receive the same utility by choosing $x_{1}^{B}$. In this case, if country $A$ offers them a smaller consumption, they all relocate to country $B$, which further increases country $A$ 's average utility. Because these individuals were being subsidized, the revenue saved can be used to restore budget feasibility in country $A$.

\section{The Possibility of Making Transfers to the Most Highly Skilled}

While equilibria with positive taxes for the most highly skilled individuals and subsidies for the lowest skilled do not exist, there are Nash equilibria in the tax competition problem being considered here. Indeed, as the next proposition shows, it is an equilibrium for each government to offer the laissez-faire allocation. In the laissez-faire allocation, an individual of type $i$ receives the unique income-consumption bundle that maximizes his utility subject to the constraint that his consumption equals his pretax income. This allocation can be implemented with a tax schedule of the form $\tau(y)=0$ for all $y$.

Proposition 3. It is a Nash equilibrium for each country to offer the laissez-faire allocation.

Proof. Suppose that both countries offer the laissez-faire allocation. We show that is not possible for one country, say $A$, to unilaterally change its offer so as to increase the average utility of its residents without violating its budget constraint.

In order to increase the average utility in country $A$ beyond its laissez-faire value, at least one type of individual, say type $h$, must receive more utility than under laissezfaire. For this to be the case, we must have $T_{h}^{A}<0$ and $N_{h}^{A}>0$. In order for the new allocation in country $A$ to be feasible, there must be some individuals of a type $k \neq h$ residing in country $A$ for which $T_{k}^{A}>0$. However, any individual of type $k$ prefers the 


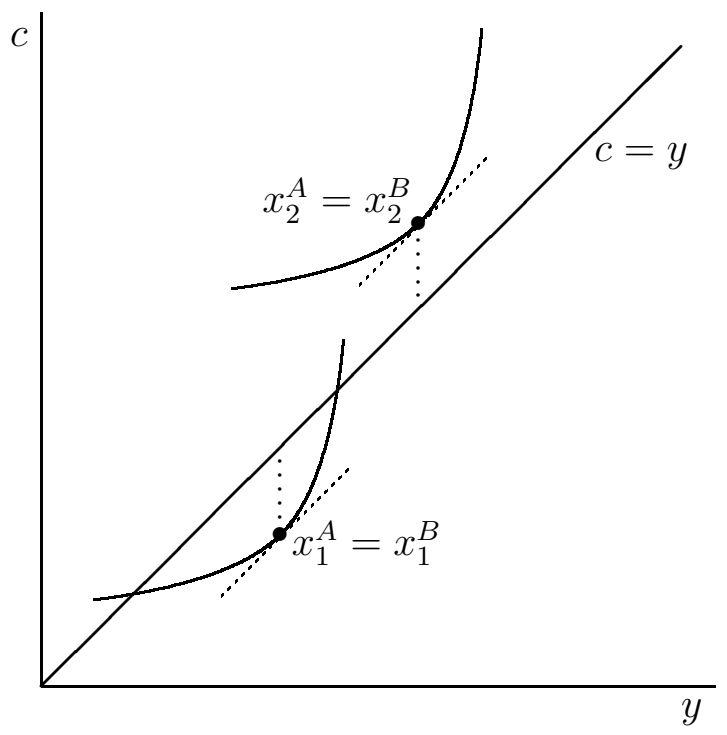

Figure 2: An equilibrium with transfers to the high skilled

laissez-faire income-consumption bundle offered in country $B$ to any bundle for which $T_{k}^{A}$ is positive. Therefore, all individuals of type $k$ choose to live in country $B$ and, hence, the new allocation must violate country $A$ 's budget constraint.

When both economies are initially tax free, the only way for a government to increase the utility of a group of individuals - either by benefiting some of its existing residents or by attracting individuals from the other country - is to offer them a transfer. However, this transfer must be financed from taxes levied on another group. Because the other country has no taxes, these would-be taxpayers emigrate.

The economic forces sustaining the laissez-faire equilibrium can also sustain equilibria in which individuals of some type less than $n$ pay positive taxes in both countries in order to make transfers to the most highly skilled individuals in the population. This point can be most simply illustrated when there are only two skill levels and two individuals with each skill.

Example. Suppose that each country offers a tax schedule that induces individuals to choose the bundles illustrated in Figure 2 and that, being indifferent between the two locations, one person of each skill type resides in each country. In this allocation, the individuals with skill $w_{1}$ (type 1 ) are taxed so as to make transfers to the individuals with skill $w_{2}$ (type 2). Furthermore, the marginal rate of substitution between income and consumption equals one for each type of individual; that is, everyone faces a zero implicit marginal tax rate on income. ${ }^{14}$ As a consequence, the only way to increase the utility

\footnotetext{
${ }^{14}$ It is straightforward to modify this example so that individuals face non-zero marginal tax rates.
} 
of one type of individual is to lower the tax paid by any individual of that type. If the government of, say, country $A$ could costlessly induce the individual of type 2 residing in country $B$ to move, it would choose to do so because this move would increase average utility by changing the composition of its residents. However, this type 2 individual will move only if given an incentive to do so in the form of an increased transfer. Should the government of country $A$ attempt to implement such a transfer scheme, it would be required to raise additional tax revenue from its resident of type 1 in order to cover the combined cost of a larger transfer for its existing type 2 resident and the additional transfer it must now pay to its new type 2 resident. Any attempt to raise taxes on the type 1 individual lowers his utility, thereby causing him to move to country $B$. Thus, the government of country $A$ cannot feasibly attract the other type 2 individual. Moreover, it has no incentive to attract the type 1 individual living in country $B$ because this would decrease average utility in country $A$. Hence, neither government can feasibly modify the allocation illustrated in Figure 2 in a welfare improving way.

\section{Concluding Remarks}

Our results confirm the validity of the race-to-the-bottom thesis when redistributive taxation is carried out by average utilitarian governments in a strategic tax-setting environment when labor is perfectly mobile and individual skills are privately known. The threat posed to redistributive taxation by subnational governments led Stigler (1957) to advocate centralizing the redistributive role of government. The same reasoning could be applied to argue that national governments should transfer the responsibility for redistributive taxation to a supranational government, such as the European Union.

The economy considered in this article has two features that make it very difficult to sustain redistribution from the rich to the poor. First, the average utilitarian social welfare function used to evaluate tax policies, when combined with the requirements of self-selection, creates an incentive for countries to attract highly skilled individuals. ${ }^{15}$ Many studies of income taxation in the presence of migration cite the revenue loss associated with emigration as a reason to provide incentives for the highly skilled not to move. See, for example, the survey by Cremer and Pestieau (2004). But, as we have emphasized, this is not the only reason why the high skilled are desirable residents; they are also desirable for the direct contribution they make to social welfare. Assuming that the governments pursue an average utilitarian objective is just one way to capture this concern. Others include the general equilibrium effects of population composition on wages or the popular view that skilled workers are particularly valuable to a country in a knowledge-based economy.

Second, the perfect mobility of labor results in the competition for skilled individuals

\footnotetext{
${ }^{15}$ In the words of Johnson (1965, p. 300), our model generates the fundamental motive for worrying about a brain drain: the highly skilled "make a contribution to national welfare that goes beyond the money value of the services they perform and that this contribution can only be enjoyed if these people are resident within the nation."
} 
being particularly intense. Costless mobility is an extreme assumption. When mobility is costless, marginal changes in government policy can induce discrete changes in population composition. Moreover, when a marginal tax change leads to nonmarginal migration across borders, the effects of this migration on either welfare or budget balance outweigh whatever within-country effects the change might have. Thus, in our model, migration ultimately trumps other considerations. However, contrary to the view expressed by Piaser (2007, p. 75), free mobility does not necessarily lead to laissez-faire. Given a strong enough desire to attract the most highly skilled, governments might actually settle on an equilibrium in which the most highly skilled receive a net transfer.

In order to make clear cut statements about optimal marginal tax rates, our model needs to be modified so that marginal changes in taxes induce marginal changes in population composition. Models with individual-specific mobility costs, like the one presented by Piaser (2007), or some form of residential attachment, as in Blackorby, Brett, and Cebreiro (2007) or Morelli, Yang, and Ye (2008), provide settings in which to examine how the interaction of labor mobility and strategic tax competition affects marginal, not just average, tax rates. The extent to which the race-to-the-bottom thesis remains valid in these settings is not yet fully explored.

\section{References}

Bhagwati, J., Hamada, K., 1982. Tax policy in the presence of emigration. Journal of Public Economics 18, 291-317.

Blackorby, C., Brett, C., Cebreiro, A., 2007. Nonlinear taxes for spatially mobile workers. International Journal of Economic Theory 3, 59-76.

Brito, D. L., Hamilton, J. A., Slutsky, S. M., Stiglitz, J. E., 1990. Pareto efficient tax structures. Oxford Economic Papers 42, 61-77.

Cremer, H., Pestieau, P., 2004. Factor mobility and redistribution. In: Henderson, J. V., Thisse, J. F. (Eds.), Handbook of Urban and Regional Economics. Vol. 4. NorthHolland, Amsterdam, pp. 2529-2560.

Dixit, A., Seade, J., 1979. Utilitarian versus egalitarian redistributions. Economics Letters $4,121-124$.

Guesnerie, R., Seade, J., 1982. Nonlinear pricing in a finite economy. Journal of Public Economics 17, 157-179.

Hamilton, J., Lozachmeur, J.-M., Pestieau, P., 2002. Rawlsian governments and the race to the bottom. Economics Bulletin 8 (2), 1-6.

Hamilton, J., Pestieau, P., 2005. Optimal income taxation and the ability distribution: Implications for migration equilibria. International Tax and Public Finance 12, 29-45.

Huber, B., 1999. Tax competition and tax coordination in an optimum income tax model. Journal of Public Economics 71, 441-458.

Johnson, H. G., 1965. The economics of the "brain drain": The Canadian case. Minerva 3, 299-311.

Krause, A., 2007. Education and taxation policies in the presence of countervailing in- 
centives. Economica, forthcoming.

Martimort, D., Stole, L., 2002. The revelation and delegation principles in common agency games. Econometrica 70, 1659-1673.

Mirrlees, J. A., 1971. An exploration in the theory of optimum income taxation. Review of Economic Studies 38, 175-208.

Mirrlees, J. A., 1982. Migration and optimal income taxes. Journal of Public Economics $18,319-341$.

Morelli, M., Yang, H., Ye, L., 2008. Competitive nonlinear taxation and constitutional choice, unpublished manuscript, Columbia Univeristy and Ohio State University.

Piaser, G., 2007. Labor mobility and income tax competition. In: Gregoriou, G., Read, C. (Eds.), International Taxation Handbook: Policy, Practice, Standards and Regulation. CIMA Publishing, Oxford, pp. 73-94.

Simula, L., Trannoy, A., 2006. Optimal non-linear income tax when highly skilled individuals vote with their feet, unpublished manuscript, Paris School of Economics.

Stigler, G. J., 1957. The tenable range of functions of local government. In: Federal Expenditure Policy for Economic Growth and Stability. Joint Economic Committee, Subcommittee on Fiscal Policy, U. S. Congress, Washington, D. C., pp. 213-219, reprinted in E. S. Phelps (Ed.), 1965. Private Wants and Public Needs. New York: Norton, 167-176.

Wildasin, D. E., 2006a. Fiscal competition. In: Weingast, B. R., Wittman, D. A. (Eds.), The Oxford Handbook of Political Economy. Oxford University Press, Oxford, pp. $502-520$.

Wildasin, D. E., 2006b. Global competition for mobile resources: Implications for equity, efficiency and political economy. CESifo Economic Studies 52, 61-110.

Wilson, J. D., 1980. The effect of potential emigration on the optimal linear income tax. Journal of Public Economics 14, 339-353.

Wilson, J. D., 1992. Optimal income taxation and international personal mobility. American Economic Review, Papers and Proceedings 82, 191-196.

Wilson, J. D., 2006. Income taxation and skilled migration: The analytical issues, unpublished manuscript, Department of Economics, Michigan State University. 